\title{
SARS-CoV-2 infection related mortality and comorbidities in a dedicated COVID-19 facility: A record based analysis from Uttar Pradesh
}

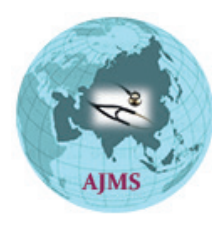

\author{
Richa Gupta1, Balvir Singh², Ashish Gautam³, Geetu Singh", Mausim Khan ${ }^{5}$, Vikas Kumar \\ ${ }^{1}$ Assistant Professor and Head, ${ }^{5}$ Postgraduate Resident, Department of Forensic Medicine, ${ }^{2}$ Professor and Head, \\ ${ }^{3}$ Associate Professor, Department of Medicine, ${ }^{4}$ Assistant Professor, Department of Community Medicine,${ }^{6}$ Assistant \\ Professor, Department of Microbiology, Sarojini Naidu Medical College, Agra, Uttar Pradesh, India
}

Background: In India, on $30^{\text {th }}$ January 2020, the first case of COVID-19 was reported, thereafter country has faced two waves with disastrous second wave. A total of about 34 million cases and 4.68 lakh deaths have been reported so far from India. Few studies have reported death rate as $5.7 \%$ among COVID-19 patients with at least one coexisting medical condition, as compared to $0.7 \%$ in patients without any comorbidity. Aims and Objectives: We aim to analyze the death audit data of 467 COVID-19 death cases considering factors of age, gender, area of residence, cause of death, related comorbidities, and relation with duration of hospital stay and presence or absence of comorbidity in COVID-19 death cases. Materials and Methods: This is an observational study from April 2020 to July 2021 which is based on records obtained from death audit reports of a dedicated COVID-19 facility at a tertiary hospital, Agra, Uttar Pradesh. The state authorities introduced a standard "COVID-19 Death Audit Proforma" on a death audit portal to audit all deaths related from COVID-19 (SARS-CoV-2) infection. Statistical analysis used: The data were recorded in Microsoft Excel and analyzed using statistical software, Microsoft Excel (Version 16.49). The results are presented accordingly in form of descriptive statistics. Results: We have reported findings from 467 COVID-19 deaths from our dedicated COVID-19 facility in the present study. Median age of deceased was found to be 57 years with $(71.9 \%)$ deaths in males, with predominantly $77.1 \%$ of patients residing in urban area. $74 \%$ of COVID-19 deaths were reported along with one or more comorbid illness at the time of admission with hypertension to be the most common comorbid disease (42.9\%) followed by diabetes $(34.5 \%)$. Median length of hospital stay is reported as 4 days. Conclusion: Our analysis from Uttar Pradesh dedicated COVID-19 facility found that comorbidities were present invariably in $74 \%$ of deaths from SAR-CoV-2 infection. Early diagnosis and timely aggressive management is pillar for reducing morbidity and mortality from COVID-19 disease.

Key words: Co-morbidity; COVID-19 deaths; Death audit; Mortality; SARS CoV-2

\section{Access this article online}

Website:

http://nepjol.info/index.php/AJMS DOI: 10.3126/ajms.v13i3.41331

E-ISSN: 2091-0576

P-ISSN: $2467-9100$

Copyright (c) 2022 Asian Journal of Medical Sciences

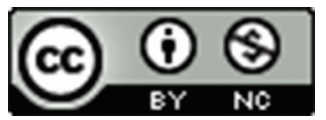

This work is licensed under a Creative Commons Attribution-NonCommercial 4.0 International License.

\section{INTRODUCTION}

From the origin of virus in Wuhan, China in December 2019 to declaration of SARS-CoV-2 as pandemic, its variants (most recent "Nu" as variant of concern) and vaccines equity and efficacy has challenged health systems across the globe. Over 262 million cases of confirmed COVID-19 have been detected globally with a mortality exceeding 5 million by the end of November 2021, as per World Health Organization (WHO). ${ }^{1}$ According to the WHO, the case fatality rate of COVID- 19 ranges from $0.1 \%$ to $25 \%$ in different health settings and regions. ${ }^{2}$ In India, on $30^{\text {th }}$ January 2020, the first case of COVID-19 was reported, thereafter country has faced two waves with disastrous second wave. A total of about 34 million cases and 4.68 lakh deaths have been reported so far from India. ${ }^{3}$ 
SARS-CoV-2 and comorbidities have been discussed in parallel in the context of severity and mortality associated with it, as a tale of cascade of immune system dysregualtion. Several studies conducted worldwide showed that the middle-aged and elderly patients with underlying co morbidities, namely, diabetes mellitus, hypertension, and cardiovascular diseases were more likely to have a severe form of COVID-19 disease with a higher mortality rate. Few studies have reported death rate as 5.7\% among COVID-19 patients with at least one co-existing medical condition, as compared to $0.7 \%$ in patients without any comorbidity. ${ }^{4,5}$

A robust data is a key for better analysis of factors contributing to COVID-19 mortality. Therefore, the state authorities in Uttar Pradesh initiated "policy of death audit for the COVID-19 deceased in the state of U.P." for keeping record and tabulation of information in a structured method concerned to all COVID-19 deceased to assess various factors related to the cause of death and other underlying or contributing disease conditions leading to mortality in COVID-19 cases. $^{6}$ Since the first reported case of COVID-19, from Agra region we have also faced the fiery two waves of COVID-19, and still have many unanswered queries, challenges, and ambiguity about COVID-19.?

\section{Aims and objectives}

The present study aimed to analyze the death audit records to study the demographic characteristics, various comorbidities contributing to the COVID-19 deaths, duration of hospital admission and mortality trends in dedicated COVID-19 facility from Uttar Pradesh.

\section{MATERIALS AND METHODS}

This is an observational study from April 2020 to July 2021 which is based on records obtained from death audit reports of a dedicated COVID-19 facility at a tertiary hospital, Agra, Uttar Pradesh. The state authorities introduced a standard "COVID-19 Death Audit Proforma" on a death audit portal to audit all deaths related to COVID-19 (SARS-CoV-2) infection. ${ }^{6}$ We analyzed the death audit data of 467 COVID-19 death cases considering factors of age, gender, area of residence, cause of death, related comorbidities and relation with duration of hospital stay and presence or absence of comorbidity in COVID-19 death cases.

\section{Study subjects}

Record analysis of 467 completed death audits of COVID-19 deaths occurring in the COVID-19 facility from April 2020 to July 2021 was included in the study.

\section{Inclusion criteria}

Death audit records of all COVID- 19 confirmed deaths reported at the COVID-19 dedicated facility of SN Medical College, Agra.

\section{Exclusion criteria}

- Any deaths where there is a clear alternative cause of death that cannot be related to COVID-19 disease (e.g. trauma) were not included in the study. (According to ICMR guideline)

- There must not be a period of complete recovery from COVID-19 amid illness and death.

- All deaths reported suspected or probable due to COVID-19 were not included in the study.

\section{Case definition8-10 \\ Death audit}

It's a technique or process of quantitative death record analysis and compiles the information pertaining to the professional activities of the hospital, as well as the quantitative analysis and evaluation of the data so collected.

\section{COVID-19 death case}

A COVID-19 death is defined for surveillance purposes as a death resulting from a clinically compatible illness in a probable or confirmed COVID-19 case unless there is a clear alternative cause of death that cannot be related to COVID-19 disease. Confirmed case: A confirmed case is a person with laboratory confirmation of infection with the COVID-19 virus, irrespective of clinical signs and symptoms. Suspected case: A patient with acute respiratory illness (that is, fever and at least one sign or symptom of respiratory disease, for example, cough or shortness of breath) with no other etiology that fully explains the clinical presentation and a history of travel to or residence in a country, area, or territory that has reported local transmission of COVID-19 disease during the 14 days prior to symptom onset. OR a patient with any acute respiratory illness and who has been a contact of a confirmed or probable case of COVID-19 disease during the 14 days prior to the onset of symptoms OR A patient with a severe acute respiratory infection (i.e., fever and at least one sign or symptom of respiratory disease, for example, cough or shortness breath), who requires hospitalization and who has no other etiology that fully explains the clinical presentation. Probable case: A probable case is a suspected case for which the report from laboratory testing for the COVID-19 virus is inconclusive. ${ }^{8,9}$

\section{Ethics}

The data in this study are the part of the audit and permission to publish the data has been taken from the Institutional ethical committee (SNMC/IEC/2021/49). Anonymity and confidentiality of the data have been 
maintained. The data were recorded in Microsoft Excel and analyzed using statistical software, Microsoft Excel (Version 16.49). The results are presented accordingly in form of descriptive statistics.

\section{RESULTS}

We have reported findings from 467 COVID-19 deaths from our dedicated COVID-19 facility in the present study. The median age of deceased was found to be 57 years (range from 4 days newborn to 87 years). Youngest COVID-19 death was reported in a female newborn referred from private hospital for premature birth and very low birth weight of $1.5 \mathrm{~kg}$, death caused due to DIC with shock. While 87 years female deceased was the eldest COVID-19 mortality and was without any comorbidity. Majority of COVID-19 deaths occurred in the age group 41-60 years $(39.2 \%)$ followed by $61-80$ years $(36.9 \%), 21-40$ years $(17.6 \%),>80$ years $(3.4 \%)$, and least number of deaths $(2.9 \%)$ was recorded from age group $0-20$ years. $60 \%$ of COVID-19 deaths in our hospital were in the age group of 0-60 years while $40 \%$ were of the elderly age group (above 60 years). In the context of gender-wise distribution, nearly $72 \%(71.9 \%)$ deaths occurred in males, while $28.1 \%$ in females. About $77.1 \%$ of COVID-19 deaths were reported from patients residing in urban area and $22.9 \%$ of patients were from rural area (Figures 1-3).

Among 467 death cases that were analyzed for with or without any pre-existing comorbid disease along with COVID-19 at the time of hospital admission; in 345 cases (74\%) of COVID-19 deaths, comorbidities were present while $122(26 \%)$ deaths were without any comorbid disease (Figure 4). Regarding various comorbidities, hypertension was found to be the most common comorbid disease present in $42.9 \%$ of deceased followed by diabetes $(34.5 \%$ ). Chronic kidney disease (CKD) was present in $13.9 \%$ of death cases. Concurrence of diabetes and hypertension, hypertension and CKD; and of diabetes, hypertension and CKD was recorded from $19.1 \%, 5.8 \%$, and $3.1 \%$ of deceased, respectively. Other comorbidities in COVID-19 deaths were chronic lung disease $(6.7 \%)$, hypothyroidism $(5.5 \%)$, cardiovascular disease $(3.8 \%)$, stroke $(3.8 \%)$, chronic liver disease $(3.2 \%)$, and malignancy $(3.2 \%)$ (Figure 5).

Time interval between hospital admission and death in COVID-19 case is showcased in Figures 6 and 7. We divided this duration into $<5$ days and more than 5 days. $32.98 \%$ of deaths were found to be within $24 \mathrm{~h}$ of hospital admission $(1.93 \%$ in $<6 \mathrm{~h}$ while $31.05 \%$ in 6 to $<24 \mathrm{~h})$. Almost $48.39 \%$ of deaths were recorded between day 1 and day 5 (27.62\% - between day 1 and 3 and $20.77 \%$ - day

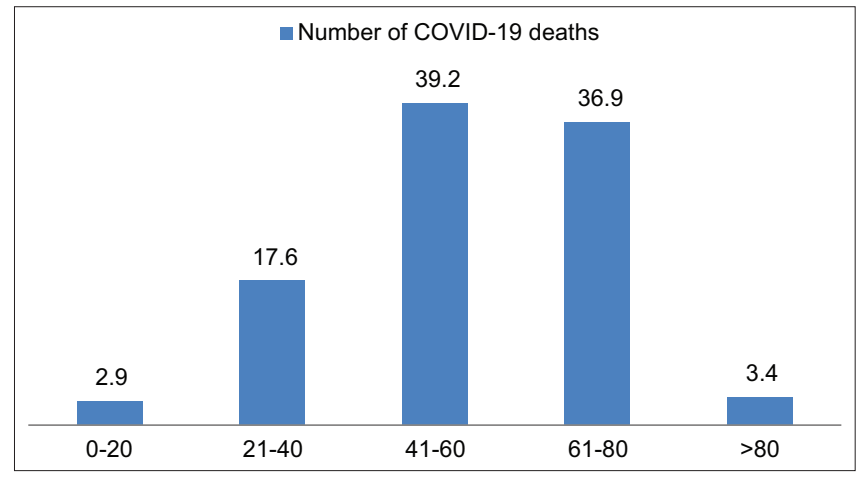

Figure 1: Age distribution of COVID-19 deaths $(\mathrm{N}=467)$

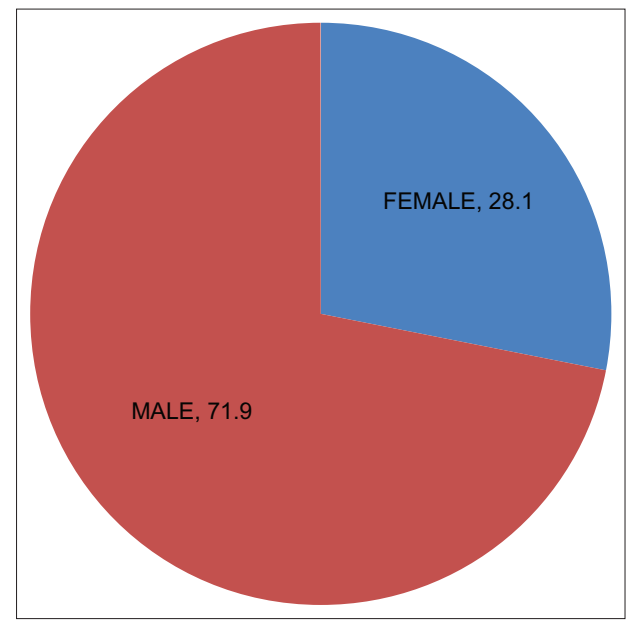

Figure 2: Sex distribution of COVID-19 deaths ( $\mathrm{N}=467)$

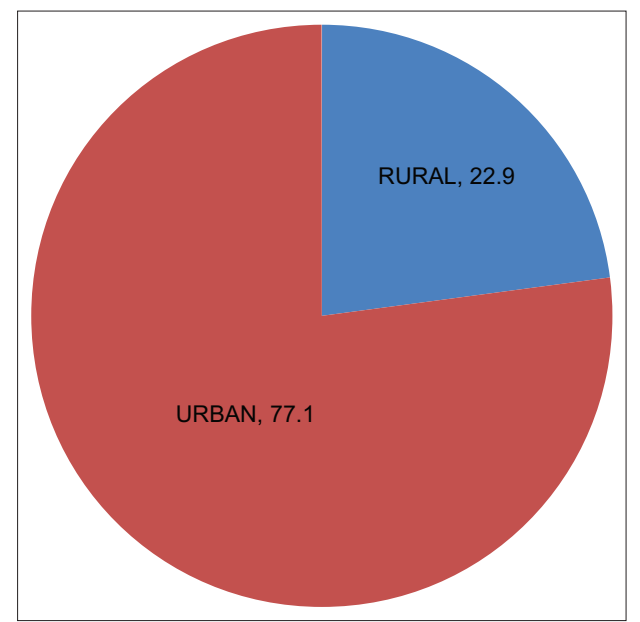

Figure 3: Area wise distribution of COVID-19 deaths $(\mathrm{N}=467)$

3 and 5), $17.77 \%$ of deaths occurred (13.7\% deaths from day 5 to 10 while $4.07 \%$ from day 10 to 15$)$. Only $0.86 \%$ of COVID-19 deaths were recorded between days 15 and $25(0.64 \%$ deaths between days 15 and 20, just one death between 20 and 25 days). We did time interval analysis in the context of the presence and absence of comorbidity; in all categories of time intervals, more COVID-19 deaths were with comorbidity. About $77.78 \%$ deceased were with 


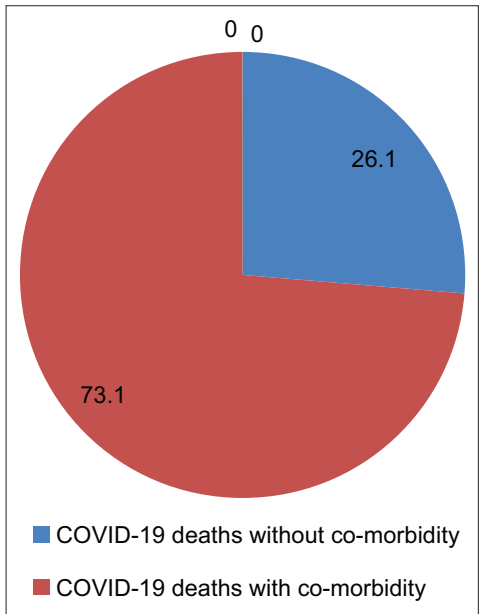

Figure 4: Distribution of COVID-19 deaths with and without comorbidities $(\mathrm{N}=467)$

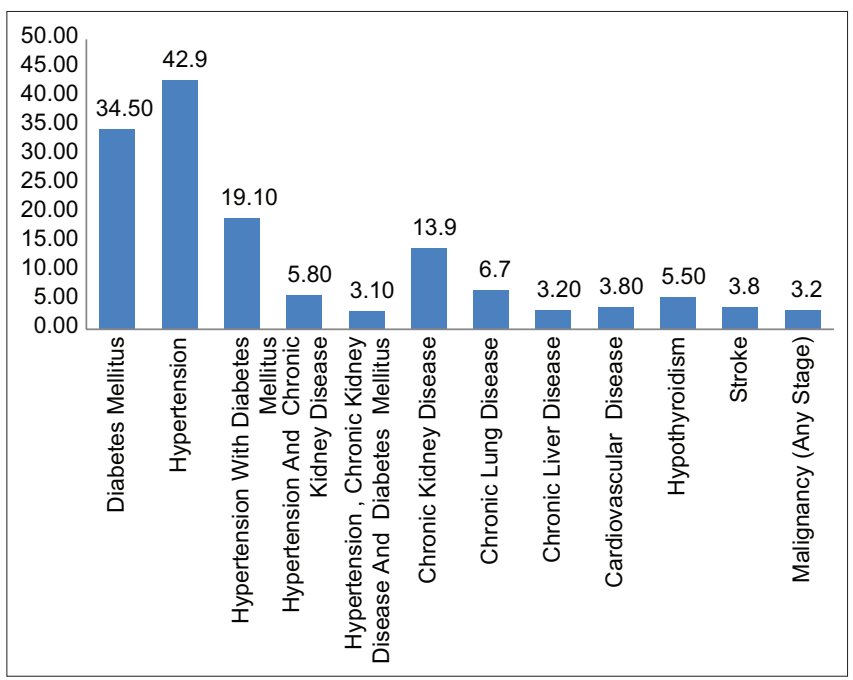

Figure 5: Distribution of various comorbidities in COVID-19 deaths with co-occurrence of comorbidities $(\mathrm{N}=345)$

comorbidity within $6 \mathrm{~h}, 63.45 \%$ in $24 \mathrm{~h}, 69 \%$ and $57.82 \%$ died between 1 to 3 days and 3 to 5 days had comorbidity. In more than $80 \%(81.25 \%$ - 5-10 days and $84.21 \%$ - 10 15 days) of deaths, comorbidity was present in between 10 and 20 days while all deaths (100\%) between 15 and 25 days had one or more comorbid condition.

Trend analysis of 467 deaths from April 2020 and July 2021 is shown in Figure 8. Maximum deaths during first wave were recorded in May 2020, second-highest in September (second peak of first wave); during second wave majority deaths were reported in April and May 2021.

\section{DISCUSSION}

COVID-19 disease and comorbidities are associated with rapid disease progression and poor survival. India is going

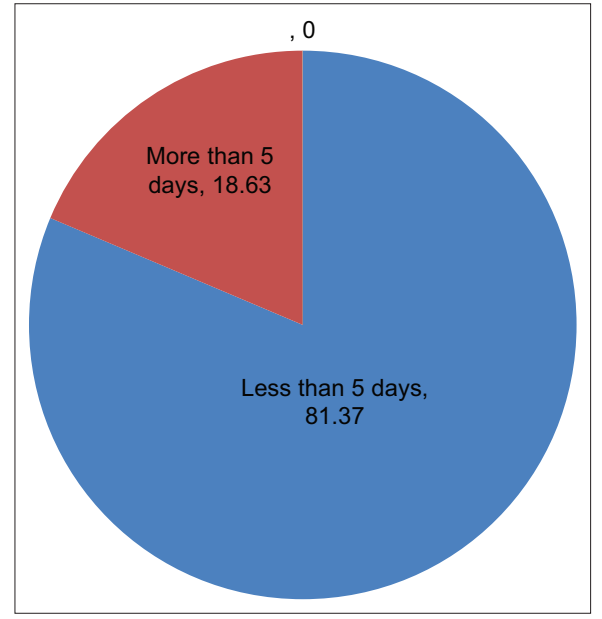

Figure 6: Distribution of COVID-19 deaths according to duration from hospital admission to death divided into less than and more than 5 days $(\mathrm{N}=467)$

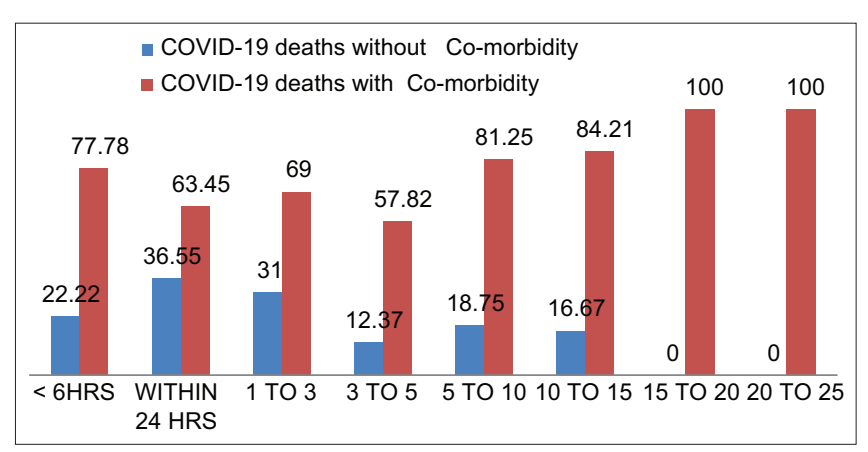

Figure 7: Distribution of COVID-19 deaths with or without co morbidity in relation to duration from hospital admission to death $(\mathrm{N}=467)$

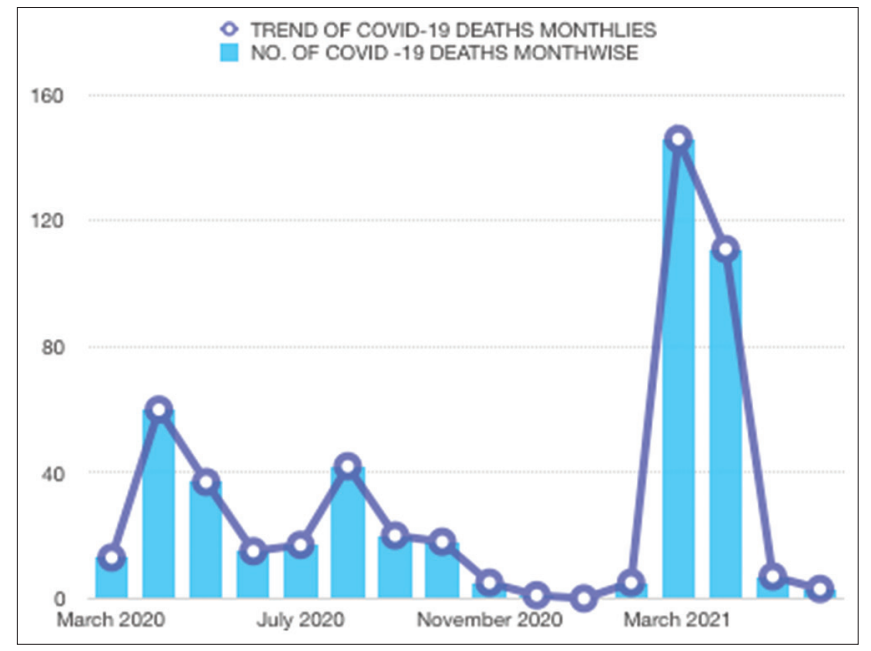

Figure 8: Monthwise Trend of COVID-19 Deaths in our hospital from April 2020 to July 2021 ( $N=467)$

through an epidemiological transition with a huge burden of non-communicable disease in country and add to this problem is undiagnosed NCDs. The present study describes mortality in COVID-19 patients in the most populous state of Uttar Pradesh in the context of demographic profile 
and co-occurrence of comorbidities in the population of Agra. In the context of demographic profile being a second most populated country in the world, India posed major challenges during the COVID-19 pandemic. The age profile in the present study revealed that the majority of deaths occurred in the age group 41-60 years (39.2\%) followed by $61-80$ years $(36.9 \%)$. An analysis highlighted, that in early phase of pandemic (till July 2020), 47\% of COVID-19 deaths in India were <60 years; a study from Tamil Nadu and Andhra Pradesh (till August 2020) found $54 \%$ of deaths under age 65 years. ${ }^{11,12}$ While early research from Mumbai, suggested increased mortality in age group $>40-60$ years, study from Pune (both waves analysis) also marked higher age groups ( $>65$ years) with higher mortality, and data from Bihar showed age-based increase in mortality with maximum mortality in the age group 60-74 years. ${ }^{13-15}$ International studies from Korea, Brazil, and Mexico also conclude mortality to be more in elderly population. ${ }^{16-18}$ Similarly, in age below 65 years only $5-13 \%$ of deaths are reported in 10 European countries and Canada and $8-24 \%$ in US states. ${ }^{19}$ Age group 41-60 years was more severely affected with COVID-19 in India which may be attributed to the fact that Indian population is young budding population with this age group at its maximum exposure of not only contacting COVID-19 disease and also high prevalence of comorbidities such as diabetes and hypertension. Children and adolescents comprised of meager $2.9 \%$ of deaths in our study (2.9\%) similar to others studies. ${ }^{20,21} \mathrm{~A}$ research with comprehensive analysis from the UK on Children COVID cases from March 2020 to February 2021 reported very low risk of death or severe COVID-19 in children. This finding of low mortality in children is also reported from India, even though seroprevalence studies highlighted higher number of children infected with SARS-CoV-2 infection. ${ }^{22,23}$

Our study reported higher proportion of deaths in male $(71.9 \%)$ in the ratio of $2.47: 1$ which was consistent with national and global data. ${ }^{13-17,20,24,25,26} \mathrm{We}$ found that majority of deaths in admitted patients belong to urban area (77.1\%). The lower mortality data among women has been reported in many studies, several explanations were cited; like protection by X chromosome and sex hormones, less risky behavior, and less exposure to outdoors. ${ }^{27}$ This study concluded that $73.9 \%$ of COVID-19 deaths were related with one or other comorbidities. Among comorbidities, hypertension was found commonly in $42.9 \%$ of deaths, followed by $34.5 \%$ deaths with diabetes mellitus and $19.1 \%$ reported concurrence of hypertension with diabetes. A meta-analysis conducted on around 64000 patient records compared effects of various comorbidities between survivors and nonsurvivors have reported all comorbid conditions except liver disease to be significantly higher in non-survivors compared to survivors, with hypertension as the highest risk predictor. ${ }^{28}$

Although many studies from different parts of India showed a high prevalence of one or more comorbidities in COVID-19 deceased diabetes being reported to be more commonly associated tailed by hypertension alone or in concurrence with diabetes and coronary artery disease. ${ }^{14,15,26,29}$ Different studies from varying regions of the world reported patients with any one of the comorbidity more likely type 2 diabetes to have increased severe form of COVID-19 causing around 70\% of deaths., ${ }^{50,31}$ One international study has reported arterial hypertension as the most prevalent chronic condition in the decedents (65.4\%), followed by obesity (38.5\%). ${ }^{31}$ Research from the US till December 2020, showcased that odds ratio of mortality with cardiovascular disease and hypertension was 40 times higher than without comorbidity. ${ }^{32}$ In $14 \%$ of cases, CKDs was found alone and in concurrence with other diseases, which is similar to studies from different parts of India reporting variation of its concurrence from $3.12 \%$ to $22 \% .{ }^{15,26,29}$ Similarly study done by The Centers for Disease Control and Prevention reported 12 times higher deaths among patients with underlying conditions compared with those without underlying conditions. ${ }^{33}$ Comorbidities was also reported linked with $70-90 \%$ of deaths found in studies from china, South Korea and Brazil. ${ }^{34-36}$

Around $26.2 \%$ of deceased in our study reported having other comorbidities such as COPD, chronic liver diseases including hepatitis, cardiovascular diseases, hypothyroidism, stroke, or any malignancy; however, the presence of these as independent comorbidity was found to be very low. This is a little higher in other studies from India, but individually there is an only minor variation from our stud. ${ }^{15,26,30}$ The early onset, poor management, and huge burden of undiagnosed non-communicable diseases such as hypertension and diabetes demands major reforms in health policy and interventions. In ongoing pandemic, population with comorbid conditions especially DM needs to be prioritized at all levels of health care, as these patients might be predisposed to develop severe form of COVID-19 disease, leading to the worst consequences and death. This has been explained by the weak immune system in diabetic individuals, more commonly observed in those with poor glycemic control. ${ }^{24}$

As estimation of time interval from onset of symptoms was a little difficult due to increased biased information, we opted for the time interval from the day of hospital admission to death to gain knowledge about the relation between the patient hospital stay and comorbidity. From our time interval analysis in the context of presence and absence of comorbidity, we concluded that in all categories 
of time intervals, more COVID-19 deaths were with comorbidity $73.9 \% .81 .4 \%$ deaths were seen in time interval $<5$ days, of which $71.8 \%$ were seen with one or more comorbidities, but we observed a relatively higher mortality within a day of hospital admission as 31.04\% compared to studies from south India which reports One-fourth of $(24.2 \%)$ deaths within a day of hospital admission. ${ }^{26}$

Study from Tamil $\mathrm{Nadu}^{37}$ reported the median time interval between hospital admission and death as 4 days which is quite similar to median hospital stay in our current study as 4 days but shorter than few studies from India which reported the median length of hospital stay of COVID-19 patients as 6-7 days. ${ }^{25,26}$ Other countries reported a slightly higher, but a wider range of 5-16 days of time interval between hospital admission and death which indicates a better access of the population of these countries to health interventions in comparison to us. ${ }^{38,39}$

We have reported month-wise trend analysis of 467 deaths from April 2020 and July 2021; the first wave of pandemic in Agra faced two peaks in the month of May and September respectively and one peak during second wave in April and May 2021. The September peak in first wave and the April-May peaks in second wave also coincide with the COVID-19 positive patient load admitted during that phase in Agra. The first peak in May during first wave can be attributed to the unpreparedness phase during onset of pandemic, our centre being a tertiary hospital and catering all the severe cases of this region along with being the epicenter of COVD-19 in Uttar Pradesh in the early phase in 2020. A study on both waves from Pune reported that the sharp decline of COVID-19 mortality during the first wave also appears to coincide with the availability of more information and revised national guidelines on clinical management such as optimal use of corticosteroid, antivirals, and appropriate early supportive treatment following hospitalization of moderate and severe COVID-19. ${ }^{14}$

\section{Limitations of the study}

Our study is limited to COVID -19 mortality from one tertiary care centre. We missed the co-morbidities like obesity which seems to impact mortality in COVID-19 patients We have also not included relation between duaration of comorbidities and COVID-19 moratlity.

\section{CONCLUSION}

Our analysis from dedicated COVID-19 facility found that comorbid condition was present invariably in about $74 \%$ of deaths from SARS-CoV-2 infection. As world has seen more than 5 million deaths and news of omicron hanging over health systems, high-risk groups should be identified and protected to prevent excess mortality. Early diagnosis timely and aggressive management is pillar for reducing morbidity and mortality from COVID-19 disease. In ongoing pandemic and huge burden of NCDs in our country, strategic guidelines need to be framed to tackle this dual burden.

\section{ACKNOWLEDGMENT}

We acknowledge all the authos for contributing in this research. Our sincere thanks to department of medicine, $\mathrm{S} \mathrm{N}$ medical college, Agra and Death audit committee members for their valuable inputs.

\section{REFERENCES}

1. WHO. WHO Coronavirus Disease (COVID-19) Dashboard. Situation by country, territory or area. Available at https:// covid19.who.int/. [Accessed on 31 October 2021]

2. World Health Organization. Estimating Mortality from COVID-19 Monograph on the Internet. Geneva: World Health Organization; 2020. Available from: https://www.who.int/news-room/ commentaries/detail/estimatingmortality-from-covid-19 [Last accessed on 2020 Aug 08].

3. Available from: https://www.worldometers.info/ coronavirus/\#countries [Last accessed on 2021 Oct 31].

4. Sanyaolu A, Okorie C, Marinkovic A, Patidar R, Younis K, Desai $P$, Hosein Z, et al. Comorbidity and its impact on patients with COVID-19. SN Compr Clin Med. 2020;???:1-8. https://doi.org/10.1007/s42399-020-00363-4

5. Rastad H, Karim H, Ejtahed HS, Tajbakhsh R, Noorisepehr M, Babaei M, et al. Risk and predictors of in hospital mortality from COVID-19 in patients with diabetes and cardiovascular disease. Diabetol Metab Syndr. 2020;12:57. https://doi.org/10.1186/s13098-020-00565-9

6. Available from: https://hospitals.upcovid19tracks.in/death-audit [Last accessed on 2021 Sep 30].

7. Available from: https://www.deccanherald.com/specials/insight/ covid-19-outbreak-in-agra-first-hit-first-on-its-feet-865733.html

8. World Health Organization. International Guidelines for Certification and Classification (Coding) of Covid-19 as Cause of Death Monograph on the Internet. Available from: https:// www.who.int/classifications/icd/Guidelines_Cause_of_Death_ COVID-19.pdf [Last accessed on 2020 Aug 08].

9. Ministry of Health and Family Welfare, Directorate General of Health Services, EMR Division. Guidance Document on Appropriate Management of Suspect/Confirmed Cases of COVID-19 Monographon the Internet. Available from: https:// www.mohfw.gov.in/pdf/Final Guidance on Mangaement of Covid cases version 2.pdf [Last accessed on 2020 Aug 08].

10. Ministry of Health and Family Welfare, Directorate General of Health Services. Guidance for Appropriate Recording of COVID-19 Related Deaths in India. Available from: https:// ncdirindia.org/Downloads/CoD_COVID-19_guidance.pdf

11. Laxminarayan R, Wahl B, Dudala SR, Gopal K, Mohan BC, Neelima S, et al. Epidemiology and transmission dynamics of COVID-19 in two Indian states. Science. 2020;370(6517):691-697. https://doi.org/370:691-7. 10.1126/science.abd7672 
12. Minu P, Ray D and Subramanian S. Decoding India's Low Covid-19 Case Fatality Rate. NBER Working Papers 27696, National Bureau of Economic Research, Inc.; 2020.

13. Dhikale PT, Chavhan SS, Adsul BB, Kinge KV, Gokhale CN and Ingale AR. Predictors for mortality of inpatients of COVID-19 in Mumbai. Int $\mathrm{J}$ Community Med Public Health. 2021;8(6):3079-3083.

https://dx.doi.org/10.18203/2394-6040.ijcmph20212019

14. Prasad B, Joshi A, Nagarkar S, Jain D, Gupte N, Shashidhara LS, et al. Burden of COVID-19 and case fatality rate in Pune India: An analysis of first and second wave of the Pandemic. MedRxiv. 2021;2021:21259225

https://doi.org/10.1101/2021.06.21.21259225

15. Ranjan A, Kumar S, Singh CM, Kumar P, Ayub A, Tiwari L, et al. Epidemiological and Clinical factors associated with mortality of confirmed COVID-19 cases admitted and treated in a tertiary care hospital of Patna, Bihar. Indian J Community Health. 2021;33(1):30-34.

https://doi.org/10.47203/IJCH.2021.v33i01.005

16. Korea Centers for Disease Control and Prevention (KCDC) Status of COVID-19 in Korea. Available from: http://ncov.mohw. go.kr/bdBoardList_Real.do. [Last accessed 30 October 2021].

17. Oliveira MH, Wong J, Lippi G and Henry BM. Analysis of clinical and demographic heterogeneity of patients dying from COVID-19 in Brazil versus China and Italy. Braz J Infect Dis. 2020;24(3):273-275.

https://doi.org/10.1016/j.bjid.2020.05.002

18. McCoy $T$ and Traiano $H$. In the Developing World, the Coronavirus is Killing Far more Young People; 2020. Available from: https://www.washingtonpost.com/world/the-Americas/ coronavirus-brazil-killingyoung-developing-world/2020/05/22/ f76d83e8-99e9-11ea-ad79-eef7cd734641_story.html [Last accessed on 2021 Sep 15].

19. Ioannidis JP, Axfors $C$ and Contopoulos-loannidis DG. Populationlevel COVID-19 mortality risk for non-elderly individuals overall and for non-elderly individuals without underlying diseases in pandemic epicenters. Environ Res. 2020;188:109890. https://doi.org/10.1016/j.envres.2020.109890

20. Tsabouri S, Makis A, Kosmeri $\mathrm{C}$ and Siomou E. Risk factors for severity in children with coronavirus disease 2019. Pediatr Clin North Am. 2021;68(1):321-338.

https://doi.org/10.1016/j.pcl.2020.07.014

21. Kumar G, Mukherjee A, Sharma RK, Menon GR, Sahu D, Wig N, et al. Clinical profile of hospitalized COVID-19 patients in first and second wave of the pandemic: Insights from an Indian registry based observational study. Indian J Med Res. 2021;123(5-6):619-628.

http://doi.org/10.4103/ijmr.ijmr_1628_21

22. Ledford $\mathrm{H}$. Deaths from Covid "incredibly rare" among children. Nature. 2021;595(7869):639. http://doi.org/10.1038/d41586-021-01897-w

23. The Hindu. COVID-19 Mortality is Rare among Children Finds Study. The Hindu; 2021.

24. Novosad P, Jain R, Campion A and Asher S. COVID-19 mortality effects of underlying health conditions in India: A modelling study. BMJ Open. 2020;10:e043165.

http://dx.doi.org/10.1136/bmjopen-2020-043165

25. Prajapati AC, Patel MM, Khanpara JH, Shukla RP, Christian DS, et al. A Hospital based cross sectional study to find out factors associated with disease severity and length of hospital stay in COVID-19 patients in Tertiary Care Hospital of Ahmedabad city. Indian J Comm Health. 2021;33(2):256-259.

https://doi.org/10.47203/IJCH.2021.v33i02.006
26. Asirvathama ES, Sarmanb CJ, Sakthivel $P$ and Saravanamurthy C. Who is dying from COVID-19 and when? An Analysis of fatalities in Tamil Nadu. India Clin Epidemiol Glob Health. 2021;9:275-279.

https://doi.org/10.1016/j.cegh.2020.09.010

27. Li Y, Jerkic M, Slutsky AS and Zhang H. Molecular mechanisms of sex bias differences in COVID-19 mortality. Crit Care. 2020;24(1):405.

https://doi.org/10.1186/s13054-020-03118-8

28. Biswas M, Rahaman S, Biswas TK, Haque Z and Ibrahim B. Association of sex, age, and comorbidities with mortality in COVID-19 patients: A systematic review and meta-analysis. Intervirology. 2021;64(1):36-47.

https://doi.org/10.1159/000512592

29. Goya PI, Sachdeva RA, Parashar L, Sikary AS and Tarique A. Are numbers deceptive? Is death auditing a solution for death analysis, among the COVID-19 deceased? A study from a dedicated COVID-19 hospital in Faridabad, Haryana. J Family Med Prim Care. 2021;10(3):1347-1352.

https://doi.org/10.4103/jfmpc.jfmpc_2063_20

30. Guan WJ, Liang WH, Zhao Y, Liang HR, Chen ZS, Li YM, et al. Comorbidity and its impact on 1590 patients with COVID-19 in China: A nationwide analysis. Eur Respir J. 2020;55(5):2000547. https://doi.org/10.1183/13993003.00547-2020

31. Sefer E, Selina G, Jana I, Michaelis EG, Bischoff P, Kunze CA, et al. Causes of death and comorbidities in hospitalized patients with COVID-19. Sci Rep. 2021;11(1):4263.

https://doi.org/10.1038/s41598-021-82862-5

32. Antos A, Kwong ML, Balmorez T, Villanueva A and Murakami S. Unusually high risks of COVID-19 mortality with age-related comorbidities: An adjusted method to improve the risk assessment of mortality using the comorbid mortality data. MedRxiv. 2021;2021:21257550.

https://doi.org/10.1101/2021.05.20.21257550

33. CDC COVID-19 Response Team. Severe outcomes among patients with coronavirus disease 2019 (COVID-19)-United States, February 12-March 16, 2020. MMWR Morb Mortal Wkly Rep. 2020;69(12):343-346.

https://doi.org/10.15585/mmwr.mm6912e2

34. Du Y, Tu L, Zhu P, Mu M, Wang R, Yang P, et al. Clinical features of 85 fatal cases of COVID-19 from Wuhan. A retrospective observational study. Am J Respir Crit Care Med. 2020;201(11):1372-1379.

https://doi.org/10.1164/rccm.202003-05430C

35. Korean Society of Infectious Diseases and Korea Centers for Disease Control and Prevention. Analysis on 54 mortality cases of coronavirus disease 2019 in the Republic of Korea from January 19 to March 10, 2020. J Korean Med Sci. 2020;35(12):e132. https://doi.org/10.3346/jkms.2020.35.e132

36. Pachiega J, Afonso AJ, Sinhorin GT, de Alencar BT, Dos Santos Miranda de Araújo M, Longhi FG, et al. Chronic heart diseases as the most prevalent comorbidities among deaths by COVID-19 in Brazil. Rev Inst Med Trop São Paulo. 2020;62:e45. https://doi.org/10.1590/S1678-9946202062045

37. Thiruvengadam G, Lakshmi $M$ and Ramanujam $R$. A study of factors affecting the length of hospital stay of COVID-19 patients by cox-proportional hazard model in a South Indian tertiary care hospital. J Prim Care Community Health. 2021;12:21501327211000231.

https//doi.org/10.1177/21501327211000231

38. Chen T, Wu D, Chen H, Yan W, Yang D, Chen G, et al. Clinical characteristics of 113 deceased patients with coronavirus 
disease 2019: retrospective study. BMJ. 2020;368:m1091. https://doi.org/10.1136/bmj.m1091

39. Giacomelli A, Ridolfo AL, Milazzo L, Oreni L, Bernacchia D, Siano M, et al. 30-day mortality in patients hospitalized with COVID-19 during the first wave of the Italian epidemic: A prospective cohort study. Pharmacol Res. 2020;158:104931.

https://doi.org/10.1016/j.phrs.2020.104931

\section{Author's Contributions:}

RG- Inception of research question, design of the study, and data analysis prepared first draft of manuscript; BS- Reviewed the literature and manuscript preparation; AG- Concept, coordination, and interpretation of results; GS- Methodology, statistical analysis, drafting and revision of the manuscript; MK- Data analysis and review of literature; VK- Revision of manuscript and coordination

\section{Work attributed to:}

Sarojini Naidu Medical College, Agra - 282 002, Uttar Pradesh, India

\section{Orcid ID:}

Dr. Richa Gupta - (1) https://orcid.org/0000-0002-2379-1672

Dr. Geetu Singh - (1) https://orcid.org/0000-0001-8546-5322

Dr. Vikas Kumar - https://orcid.org/0000-0002-4787-6224

Source of Support: Nil, Conflicts of Interest: None declared. 